\title{
An Evaluation of the Effect of a One or Two-Step Gestational Diabetes Mellitus Screening Program on Obstetric and Neonatal Outcomes in Pregnancies
}

\author{
Sedat AKGOL ${ }^{1}$, Mehmet OBUT ${ }^{1}$, Ihsan BAGLI' ${ }^{\text {, Bekir KAHVECI }}{ }^{1}$, Mehmet Sukru BUDAK \\ Diyarbakir, Turkey
}

\begin{abstract}
OBJECTIVES: The aim of this study was to compare the obstetric and neonatal outcomes of pregnant women who were screened with one or two-step screening programs for diagnosis of gestational diabetes mellitus.

STUDY DESIGN: A retrospective evaluation was made of pregnant women who were screened with one step [75 g oral glucose tolerance test] or two-step screening programs [50 g oral glucose challenge test and $100 \mathrm{~g}$ oral glucose tolerance test] depending on the preference of the physician between September 2016 and August 2017.

RESULTS: The one-step screening program was applied to $34.1 \%(n: 1358)$ of the pregnancies and the remaining $65.9 \%$ ( $n=2623$ ) were screened using the two-step program. The following results were obtained for the pregnant women applied with the one and two-step screening programs, respectively; mean age: $29.37 \pm 7.6$ years and $28.1 \pm 6.2$ years, gestational diabetes mellitus: $8.8 \%$ and $4.8 \%$, preterm birth: $5.2 \%$ and $6.9 \%$, term birth: $89.8 \%$ and $85.5 \%$, postterm birth: $5 \%$ and $7.6 \%$, vaginal delivery: $74.8 \%$ and $67.5 \%$, caesarean section delivery: $25.2 \%$ and $32.5 \%$, birth weight: $3389 \pm 432 \mathrm{~g}$ and 3234.1 $\pm 415.9 \mathrm{~g}$, and mean 5-minute APGAR score: $9.1 \pm 0.4$ and $9.2 \pm 0.7$. Comparisons showed statistically significant differences between the groups.

CONCLUSION: The study results showed a significantly higher rate of gestational diabetes mellitus diagnosis for the pregnant women screened with the one-step screening program than the two-step screening program. Although the mean maternal age was significantly higher in the pregnant women screened with the one-step screening program, these pregnancies were observed to have better outcomes (low rates of preterm birth, postterm birth, caesarean delivery and high rates of term birth, vaginal delivery). These results can be attributed to the early referral to a treatment program and follow-up, even though more cases of gestational diabetes mellitus were diagnosed with the one-step screening program.
\end{abstract}

Keywords: Gestational diabetes mellitus, Obstetric and neonatal outcomes, One-step screening program, Prevalence, Two-step screening program

Gynecol Obstet Reprod Med 2019;25(2):62-66

${ }^{I}$ Department of Obstetrics and Gynecology, Health Sciences University Gazi Yasargil Education and Research Hospital, Diyarbakir, Turkey

Address of Correspondence: Mehmet Sukru Budak

University of Health Sciences Diyarbakir Gazi Yasargil Training and Research

Hospital Department of Obstetrics and Gynecology 21500 Diyarbakir, Turkey dr.budakms@gmail.com

Submitted for Publication: 31.05 .2018

Accepted for Publication:

ORCID IDs of the authors:

S.A.: 0000-0001-8609-3049, M.O.:0000-0002-6925-4784

I.B.: 0000-0002-3195-9164, B.K.: 0000-0002-8729-1669 M.S.B.: 0000-0001-7328-4188

\begin{tabular}{|c|c|}
\hline \begin{tabular}{c} 
Quick Response Code: \\
\cline { 2 - 2 }
\end{tabular} & Access this article online \\
\cline { 2 - 2 } & $\begin{array}{l}\text { Website: www.gorm.com.tr } \\
\text { e- mail: info@gorm.com.tr }\end{array}$ \\
\cline { 2 - 3 } & DOI:10.21613/GORM.2018.791 \\
\hline
\end{tabular}

How to cite this article: Akgol S. Obut M. Bagli I. Kahveci B. Budak MS. An Evaluation of the Effect of a One or Two-Step Gestational Diabetes Mellitus Screening Program on Obstetric and Neonatal Outcomes in Pregnancies. Gynecol Obstet Reprod Med 2019;25(2):62-66

\section{Introduction}

Although gestational diabetes mellitus (GDM) affects 2$5 \%$ of pregnancies, the frequency reaches $18 \%$ according to the population and diagnostic criteria applied (1-4). Complications such as fetal macrosomia, shoulder dystocia, polyhydramnios, operative delivery, pre-eclampsia, increased cesarean ratios and poor neonatal outcomes have been shown to develop in gestations with GDM (5). Studies have shown that these complications in GDM-developed pregnancies, can be reduced if GDM diagnoses are established and treated early with screening programs in all pregnancies (6-7). Nowadays, one and twostep screening programs are the most frequently used approaches for GDM screening. In the one-step screening program, all pregnancies are screened with the $75 \mathrm{~g}$ oral glucose tolerance test (OGTT) at between 24 and 28 weeks of gestation while in the two-step screening, this is performed using the 50 g oral glucose challenge test (OGCT) and according to the result of the 1-hour blood glucose value, the $100 \mathrm{~g}$ OGTT is per- 
formed (8-9). Different diagnostic criteria can be used to diagnose GDM in these two screening programs (10).

There have been many changes during the past century related to the use of screening methods and criteria in GDM screening, and many international meetings and workshops have been organized to determine the best screening methods and criteria to overcome the controversial situation that still exists worldwide. (8-9,11-13). In addition, several recent studies comparing the one step and two-step screening programs have been conducted (14-16). As a result of these meetings and studies, the use of different screening programs in GDM screening is recommended by international organizations. The American College of Obstetricians and Gynecologists (ACOG) recommend the two-step screening program (9) while the International Association of Diabetes and Pregnancy Study Groups (IADPSG), the American Diabetes Association (ADA) and the World Health Organization (WHO) recommend the one-step screening program $(2,8,11)$. Therefore, there are different opinions about the screening program to be used to diagnose GDM between centers and even between physicians working in the same centers.

The aim of this study was to compare the obstetric and neonatal outcomes of pregnant women who were screened with one or two-step screening programs for the diagnosis of GDM.

\section{Material and Method}

This retrospective cohort study was approved by the ethics committee (\# 2018-29). The patients included were pregnant women at 24-28 weeks of gestation with a single living pregnancy who presented at the Gazi Yaşargil Training and Research Hospital, Health Sciences University Medical Faculty, between September 2016 and August 2017 and were applied with a one or two-step screening program depending on the preference of the physician to diagnose GDM.

Obstetric ultrasound (OB-USG) was performed on all the cases before GDM screening. The OB-USG results were compared with the last menstrual period and 1st trimester OB-USG to determine the gestational week. In the one-step screening program, the $75 \mathrm{~g}$ OGTT was applied following an 8-12 hour fasting period. GDM diagnosis was established on the observation of one high result from the fasting, 1-hour and 2-hour blood glucose values (fasting $\geq 92 \mathrm{mg} / \mathrm{dL}, 1$-h blood glucose $\geq 180$ $\mathrm{mg} / \mathrm{dL}$ and 2-h blood glucose $\geq 153 \mathrm{mg} / \mathrm{dL})(8,17)$. In the twostep screening program, the pregnant women with 1-hour blood glucose value $<140 \mathrm{mg} / \mathrm{dL}$ after $50 \mathrm{~g}$ OGCT were considered normal; $100 \mathrm{~g}$ OGTT was performed in pregnant women with a 1-hour blood value of 140-199 mg/dL after $50 \mathrm{~g} \mathrm{OGCT,} \mathrm{and}$ those with 1-hour blood glucose of $\geq 200 \mathrm{mg} / \mathrm{dL}$ were evaluated as GDM. Of the pregnant women administered with $100 \mathrm{~g}$ OGTT, GDM diagnosis was established for those with two or more high blood sugar values from four (fasting blood glucose level: $95 \mathrm{mg} / \mathrm{dL}$, 1-hour $180 \mathrm{mg} / \mathrm{dL}, 2$-hour $155 \mathrm{mg} / \mathrm{dL}$ and 3hour $140 \mathrm{mg} / \mathrm{dL}$ ) according to the Carpenter-Coustan Conversion criteria (18). The comparison of the GDM prevalence was made between the one and two-step screening programs applied for GDM diagnosis. The groups were compared based on obstetrics and neonatal outcomes. The pregnant patients applied with the one and two-step screening programs were compared in terms of age, pre-eclampsia, type of delivery (vaginal or caesarean delivery), gestational age at birth, birth weight, 5-minute APGAR, 5-minute APGAR $<7$, pre-term birth $(<37$ gestational weeks), term birth, post-term birth $(>42$ gestational weeks), and small for gestational age (SGA) [newborns defined as birthweight $<10^{\text {th }}$ percentile according to the gestational age (19)], large for gestational age (LGA)[birthweight $>90^{\text {th }}$ percentile according to the gestational age (20)]. In addition, a comparison of these parameters were made between those with normal screening results and those with GDM diagnoses. Multiple pregnancies, patients with pre-pregnancy diagnosis of diabetes mellitus, pregnancies with chronic disease (asthma, corticosteroid use, chronic hypertension) and those with known fetal anomalies were not included in the study.

\section{Statistical Analysis}

Continuous variables were stated with descriptive statistics of mean, standard deviation, median, minimum and maximum values. The Mann Whitney U-test was used to compare two independent variables with non-normal distribution. The ChiSquare test was used to examine relationships between categorical variables. A value of $p<0.05$ was accepted as statistically significant.

\section{Results}

Evaluation was made of a total of 3981 singleton pregnancies at 24-28 gestational weeks. Of these, 34.1\% $(n=1358)$ were screened with the one-step screening program and $65.9 \%$ ( $n=2623$ ) were screened with the two-step screening program to establish GDM diagnosis during this study period.

The following results were obtained for the pregnant women applied with the one and two-step screening programs, respectively; mean age: 29.377 .6 years and $28.1 \pm 6.2$ years, GDM: $8.8 \%$ and $4.8 \%$, pre-term birth: $5.2 \%$ and $6.9 \%$, term birth: $89.8 \%$ and $85.5 \%$, post-term birth: $5 \%$ and $7.6 \%$, vaginal delivery: $74.8 \%$ and $67.5 \%$, caesarean section delivery: $25.2 \%$ and $32.5 \%$, birth weight: $3389 \pm 432$ gr and $3234.1 \pm$ 415.9 gr and mean 5-minute APGAR score: $9.1 \pm 0.4$ and $9.2 \pm$ 0.7. Comparisons showed statistically significant differences between the groups. The following results were also obtained for the two groups respectively; mean gestational age: $38.8 \pm 2.4$ weeks and $38.9 \pm 1.7$ weeks, 5-minute APGAR <7: $1.4 \%$ and $1 \%$, SGA: $5 \%$ and $4.1 \%$, LGA: $5.5 \%$ and $6.02 \%$, preeclampsia: $4.7 \%$ and $5 \%$ and no significant difference was observed between the groups (Table I).

Distribution of characteristic features of pregnancies with GDM diagnosis by one or two-step GDM screening programs 
were summarized in table II. In these pregnancies cesarean rates were $43.7 \%$ when GDM diagnosis was made with onestep screening program, and $\% 48.4$ when it was diagnosed with two-step screening program $(p<0.05)$.

Distribution of characteristic features of the pregnant women who have normal results of one or two-step GDM screening programs were summarized in table III. The following results were obtained for the pregnant women who have normal results of one or two-step GDM screening programs, respectively; mean age: $28.9+7.7$ years and $27.9+6.2$ years, term birth: $90.4 \%$ and $86.1 \%$, post-term birth: $4.8 \%$ and $7.7 \%$, vaginal delivery: $76.6 \%$ and $68.3 \%$, caesarean section delivery: $23.4 \%$ and $31.6 \%$, birth weight: $3301.9+385.6 \mathrm{~g}$ and $3202.4+399.4 \mathrm{~g}$ and mean 5-minute APGAR score: $9.05+0.4$ and $9.2+0.6$. Comparisons showed statistically significant differences between the groups. The following results were also obtained for the two groups respectively; preterm birth: $4.8 \%$ and $6.2 \%$, mean gestational age: $38.8 \pm 2.4$ weeks and $39 \pm 1.7$ weeks, 5-minute APGAR $<7: 1.2 \%$ and $0.8 \%$, SGA: $4.4 \%$ and $4.0 \%$, LGA: $3.8 \%$ and $5.4 \%$, preeclampsia: $4.0 \%$ and $4.6 \%$ and no significant difference was observed between the groups (Table III).

Table I: Distribution of characteristic features of the pregnant women applied with one or two-step gestational diabetes mellitus screening programs

\begin{tabular}{|c|c|c|c|}
\hline & $\begin{array}{l}\text { One-step } \\
n=1358\end{array}$ & $\begin{array}{l}\text { Two-step } \\
n=2623\end{array}$ & $p$ \\
\hline Age (year), [mean \pm SD] & $29.37 \pm 7,6$ & $28.1 \pm 6.2$ & $<0.001^{1}$ \\
\hline GDM, n (\%) & $119(8.8)$ & $126(4.8)$ & $<0.001^{2}$ \\
\hline Gestational age (wk), [mean] & $38.8 \pm 2,4$ & $38.9 \pm 1.7$ & $0.155^{1}$ \\
\hline -preterm birth (<37wk), n, (\%) & $70(5.2)$ & $180(6.9)$ & $0.043^{2}$ \\
\hline -term birth (37wk-41wk 6d), n (\%) & $1220(89.8)$ & $2244(85.5)$ & $<0.001^{2}$ \\
\hline -postterm birth ( $\geq 42 w k), n(\%)$ & $68(5.0)$ & $199(7.6)$ & $0.002^{2}$ \\
\hline \multicolumn{4}{|l|}{ Type of delivery, n, (\%) } \\
\hline -vaginal, n (\%) & $1016(74,8)$ & $1772(67.5)$ & $0.001^{2}$ \\
\hline -caesarean, n (\%) & $342(25,2)$ & $851(32.5)$ & $<0.001^{2}$ \\
\hline Birth weight, g, [mean \pm SD] & $3389,7 \pm 432$ & $3234.1 \pm 415.9$ & $<0.001^{1}$ \\
\hline 5-min. APGAR [mean \pm SD] & $9,1 \pm 0,4$ & $9.2 \pm 0.7$ & $<0.001^{1}$ \\
\hline 5-min. APGAR<7, n, (\%) & $19(1,4)$ & $27(1.0)$ & $0.331^{2}$ \\
\hline SGA, n (\%) & $68(5,0)$ & $107(4.1)$ & $0.218^{2}$ \\
\hline LGA, n (\%) & $75(5,5)$ & $158(6.02)$ & $<0.553^{2}$ \\
\hline Pre-eclampsia, n (\%) & $64(4,7)$ & $131(5.0)$ & $0.735^{2}$ \\
\hline
\end{tabular}

SGA: Small for gestational age, LGA: Large for gestational age, GDM: Gestational diabetes mellitus, Wk: Week, Min: Minute, d: day, g: gram, Mann-Whitney U1', Chi-Square ${ }^{2}$

Table II: Distribution of characteristic features of pregnancies with gestational diabetes mellitus diagnosis by one or two-step gestational diabetes mellitus screening programs

\begin{tabular}{|c|c|c|c|}
\hline & $\begin{array}{l}\text { One step } \\
n=119\end{array}$ & $\begin{array}{l}\text { Two step } \\
n=126\end{array}$ & $p$ \\
\hline Age (year), [mean \pm SD] & $32.31 \pm 5.60$ & $32.63 \pm 5.02$ & $0.155^{1}$ \\
\hline Gestational age (wk), [mean] & $38.8 \pm 2.4$ & $38.9 \pm 1.7$ & $0.155^{1}$ \\
\hline -pre-term (<37wk), n, (\%) & $11(9.2)$ & $12(9.5)$ & $0.735^{2}$ \\
\hline -term (37wk-41wk6d), n (\%) & $105(88.3)$ & $110(87.4)$ & $0.218^{2}$ \\
\hline -postterm( $\geq 42 w k), n(\%)$ & $3(2.5)$ & $4(3.1)$ & $0,331^{2}$ \\
\hline \multicolumn{4}{|l|}{ Type of delivery, n, (\%) } \\
\hline -vaginal, n (\%) & $67(56.3)$ & $65(51.6)$ & $0.001^{2}$ \\
\hline -cesarean, n (\%) & $52(43.7)$ & $61(48.4)$ & $0.001^{2}$ \\
\hline Birth weight, g, [mean \pm SD] & $3427.7 \pm 432$ & $3434.1 \pm 415.9$ & $0.735^{2}$ \\
\hline 5 min. APGAR [mean \pm SD] & $9.1 \pm 0.4$ & $9.05 \pm 0.49$ & $0.309^{2}$ \\
\hline $5 \mathrm{~min}$. APGAR<7, n, (\%) & $4(3.4)$ & $6(4.7)$ & $0.218^{2}$ \\
\hline SGA, n (\%) & $5(4.2)$ & $6(4.7)$ & $0.853^{2}$ \\
\hline LGA, n (\%) & $20(16.8)$ & $23(18.25)$ & $0.218^{2}$ \\
\hline Pre-eclampsia, n (\%) & $14(11.7)$ & $16(12.6)$ & $0.309^{2}$ \\
\hline
\end{tabular}

SGA: Small for gestational age, LGA: Large for gestational age, GDM: Gestational diabetes mellitus, wk: Week, min: Minute, d: Day, g: Gram, MannWhitney U1', Chi-Square ${ }^{2}$ 
Table III: Distribution of characteristic features of the pregnant women who have normal results of one or two-step gestational diabetes mellitus screening programs

\begin{tabular}{|c|c|c|c|}
\hline & $\begin{array}{l}\text { One step } \\
n=119\end{array}$ & $\begin{array}{l}\text { Two step } \\
n=126\end{array}$ & $p$ \\
\hline Age (year), [mean \pm SD] & $28.9 \pm 7.7$ & $27.9 \pm 6.2$ & $<0.0011$ \\
\hline Gestational age (wk), [mean] & $38.8 \pm 2.3$ & $39 \pm 1.7$ & $0.155^{1}$ \\
\hline- preterm(<37wk), n, (\%) & $60(4.8)$ & $154(6.2)$ & $0.097^{2}$ \\
\hline -term(37wk-41wk6d), n (\%) & $1120(90.4)$ & $2152(86.1)$ & $0.001^{2}$ \\
\hline -postterm( $\geq 42 w k), n(\%)$ & $59(4.8)$ & $191(7.7)$ & $0.002^{2}$ \\
\hline \multicolumn{4}{|l|}{ Type of delivery, n, (\%) } \\
\hline -vaginal, n (\%) & $949(76.6)$ & 1705 (68.3) & $<0.001^{2}$ \\
\hline -cesarean, n (\%) & $290(23.4)$ & $790(31.6)$ & $<0.001^{2}$ \\
\hline Birth weight, g, [mean \pm SD] & $3301.9 \pm 385.6$ & $3202.4 \pm 399.4$ & $<0.001^{1}$ \\
\hline 5 min. APGAR [mean \pm SD] & $9.05 \pm 0.4$ & $9.2 \pm 0.6$ & $<0.001^{1}$ \\
\hline $5 \mathrm{~min}$. APGAR $<7, \mathrm{n},(\%)$ & $15(1.2)$ & $21(0.8)$ & $0.309^{2}$ \\
\hline SGA, n (\%) & $55(4.4)$ & $101(4.0)$ & $0.638^{2}$ \\
\hline LGA, n (\%) & $48(3.8)$ & $135(5.4)$ & $0.218^{2}$ \\
\hline Pre-eclampsia, n (\%) & $50(4.0)$ & $115(4.6)$ & $0.553^{2}$ \\
\hline
\end{tabular}

SGA: Small for gestational age, LGA: Large for gestational age, GDM: Gestational diabetes mellitus, wk: Week, min: Minute, d: Day, g: Gram, MannWhitney $U^{1}$, Chi-Square ${ }^{2}$

\section{Discussion}

The results of this study showed that in the screening program with one - step, more pregnant women were diagnosed with GDM compared to the two-step screening program and this result is similar to the findings of Sevket et al (15) and Saccone et al (21). When these studies are examined in detail, Sevket et al (15) reported a GDM rate of $14.5 \%$ for the onestep screening program and $6 \%$ for the two-step screening program, while Saccone et al (21) reported these rates as $8.4 \%$ and $4.3 \%$, respectively. In the current study, these rates were $8.8 \%$ and $4.8 \%$, respectively, and although they were similar to the results of Saccone et al (21), they were lower than the results of Sevket et al (15) but comparable with the GDM prevalence reported in the literature (1-4).

In the current study, preterm birth and caesarean delivery rates were significantly lower in pregnant women who were screened with the one-step screening program compared to the two-step screening program, which is similar to the significant decrease in preterm birth and caesarean delivery rates reported in the Saccone et al study (21). However, in the one-step screening program of the current study, postterm birth rates and 5-minute APGAR scores were significantly lower than those of the two-step screening program, while term birth and mean birth weight were significantly higher. Unlike the current study, Saccone et al (21) found that the mean birth weight was significantly lower in the one-step screening program. In the current study, the low rate of caesarean delivery of the pregnant women screened with the one-step screening program can be attributed to the preterm delivery rate which was significantly lower in this group.
While the current study showed no difference in the 5minute APGAR $<7$, SGA, LGA, and pre-eclampsia rates between the one-step and two-step screening programs, Saccone et al (21) reported a significantly lower LGA rate in the onestep screening program.

Many studies have shown that increased maternal age leads to adverse obstetric and neonatal outcomes (22-25). In the current study, although the mean maternal age was significantly higher in the pregnancies screened with the one-step screening program compared to those who were screened with the twostep program, there was no significant increase in adverse pregnancy outcomes, and there was a significant decrease in preterm birth, postterm birth and caesarean delivery rates.

In the current study, cesarean ratios in GDM diagnoses with two-step GDM screening program were significantly higher than those with GDM diagnosis in one-step GDM screening program. In addition, postterm birth and caesarean delivery rate were significantly higher in pregnant women who have normal result of GDM screening program by twostep screening program than one-step screening group.

In conclusion, the results of the current study showed that a significantly higher rate of GDM diagnosis was established for pregnant women screened with the one-step screening program compared to the two-step screening program. Although the mean maternal age was significantly higher in the one-step screening group, better pregnancy outcomes were observed in these pregnancies (low rates of preterm birth, postterm birth, caesarean delivery and high rates of term birth, vaginal delivery). These results can be attributed to the early referral to a treatment program and follow-up, even though more cases of GDM were diagnosed with the one-step screening program. 
: Conflict of interest: We have no conflict of interest to declare.

Funding: None

Ethics: The study was approved by the Ethics Committee of University of Health Sciences Diyarbakir Gazi Yasargil Education and Research Hospital in Turkey (approval number: 2018-29)

Acknowledgements: This study was presented as an oral presentation at the $16^{\text {th }}$ National Congress of Gynecology and Obstetrics in Antalya

\section{References}

1. Metzger BE, Buchanan TA, Coustan DR, de Leiva A, Dunger DB, Hadden DR, et al. Summary and recommendations of the Fifth International Workshop -Conference on Gestational Diabetes Mellitus. Diabetes Care. 2007;30 (Supplement): 251-60.

2. American Diabetes Association. Standards of medical care in diabetes. Diabetes Care. 2011;34(1):11-61.

3. Moses RG. The recurrence rate of gestational diabetes in subsequent pregnancies. Diabetes Care. 1996;19(12): 1348-50.

4. American Diabetes Association. Standards of medical care in diabetes. Diabetes Care. 2010;33(1):11-61.

5. Casey BM, Lucas MJ, Mcintire, DD, Leveno KJ. Pregnacy outcomes in women with gestational diabetes compared with the general obstetric population. Obstet Gynecol. 1997;90(6):869-73.

6. Di Cianni G, Volpe L, Casadidio I, Bottone P, Marselli L, Lencioni $\mathrm{C}$, et al. Universal screening and intensive metabolic management of gestational diabetes: cost-effectiveness in Italy. Acta Diabetol. 2002;39(2):69-73.

7. Kitzmiller JL. Cost analysis of diagnosis and treatment of gestational diabetes. Clin Obstet Gynecol. 2000;43(1) :140-53.

8. International Association of Diabetes and Pregnancy Study Groups Consensus Panel. Metzger BE, Gabbe SG, Persson B, Buchanan TA, Catalano PA, Damm P, et al. International association of diabetes and pregnancy study groups recommendations on the diagnosis and classification of hyperglycemia in pregnancy. Diabetes Care 2010; 33(3):676-82.

9. Committee on Practice. Bulletins-Obstetrics. Practice Bulletin No. 137 Gestational diabetes mellitus. Obstet Gynecol 2013;122(2 Pt 1):406-16.

10. Agarwal MM, Dhatt GS, Punnose J, Koster G. Gestational diabetes: dilemma caused by multiple international diagnostic criteria. Diabet Med. 2005;22(12):1731-36.

11. WHO 2013. Diagnostic Criteria and Classification of Hyperglycaemia First Detected in Pregnancy. Available online at: http://apps.who.int/iris/bitstream/10665/85975/ 1/WHO_NMH_MND_13.2_eng.pdf (Accessed February, $25,2017)$.
12. Hod M, Kapur A, Sacks DA, Hadar E, Agarwal M, Di Renzo GC, et al. The International Federation of Gynecology and Obstetrics (FIGO) Initiative on gestational diabetes mellitus: a pragmatic guide for diagnosis, management, and care. Int J Gynaecol Obstet. 2015;131 (Suppl 3): S173-211.

13. American Diabetes Association. Classification and diagnosis of diabetes. Diabetes Care 2017;40(Suppl) 1:11-24

14. Meltzer SJ, Snyder J, Penrod JR, Nudi M, Morin L. Gestational diabetes mellitus screening and diagnosis:a prospective randomised controlled trial comparing costs of onestep and two-step methods. BJOG. 2010;117(4):407-15.

15. Sevket O, Ates S, Uysal O, Molla T, Dansuk R, Kelekci S. To evaluate the prevalence and clinical outcomes using a one-step method versus a two-step method to screen gestational diabetes mellitus. J Matern Fetal Neonatal Med. 2014;27(1):36-41.

16. Scifres CM, Abebe KZ, Jones KA, Comer DM, Costacou T, Freiberg MS, et al. Gestational diabetes diagnostic methods (GD2M) pilot randomized trial. Matern Child Health J. 2015;19(7):1472-80.

17. The HAPO Study Cooperative Research Group. Hyperglycemia and adverse pregnancy outcomes. N Engl J Med. 2008;358(19):1991-2002.

18. Carpenter MW, Coustan DR. Criteria for screening tests for gestational diabetes. Am J Obstet Gynecol. 1982; 144(7):768-73.

19. American College of Obstetricians and Gynecologists. ACOG Practice bulletin no. 134: fetal growth restriction. Obstet Gynecol. 2013;121(5):1122-33.

20. American College of Obstetricians and Gynecologists' Committee on Practice Bulletins - Obstetrics. Practice bulletin no. 173: Fetal Macrosomia. Obstet Gynecol. 2016;128(5):195-209.

21. Saccone G, Caissutti C, Khalifeh A, Meltzer S, Scifres C, Simhan HN, et al. One step versus two step approach for gestational diabetes screening: systematic review and meta-analysis of the randomized trials. J Matern Fetal Neonatal Med 2019;32(9):1547-55.

22. Jacobsson B, Ladfors L, Milsom I. Advanced maternal age and adverse perinatal outcome. Obstet Gynecol. 2004; 104(4):727-33.

23. Cleary-Goldman J, Malone FD, Vidaver J, Ball RH, Nyberg DA, Comstock CH, et al. Impact of maternal age on obstetric outcome. Obstet Gynecol. 2005;105(5 Pt 1):98390 .

24. Luke B, Brown MB. Elevated risks of pregnancy complications and adverse outcomes with increasing maternal age. Hum Reprod. 2007;22(5):1264-72.

25. Hsieh TT, Liou JD, Hsu JJ, Lo LM, Chen SF, Hung TH. Advanced maternal age and adverse perinatal outcomes in an Asian population. Eur J Obstet Gynecol Reprod Biol. 2010;148(1):21-6. 